\title{
Dealing with the Daily Emergency Care: A Case among the Waste Pickers in Surabaya
}

\author{
Loetfia Dwi Rahariyani $^{1}$, Nikmatul Fadilah ${ }^{2}$, Yohanes Kambaru Windi ${ }^{3,4}$, Nursalam ${ }^{5}$ \\ ${ }_{1,2,3}$ Polytechnic of Health Surabaya, Ministry of Health, Indonesia \\ ${ }^{4}$ Department of Epidemiology and Preventive Medicine, SPHPM, FMNHS Monash University Australia \\ ${ }^{5}$ Department of Nursing Seiences, Airlangga University, Indonesia
}

\begin{tabular}{l} 
Article Info \\
\hline Article history: \\
Received Apr 25, 2016 \\
Revised Jul 20, 2016 \\
Accepted Jul 26, 2016 \\
\hline Keyword: \\
Capability \\
Emergency care \\
Knowledge \\
Waste pickers \\
\hline
\end{tabular}

\begin{abstract}
Waste pickers are those who collect, sort and sell recyclable waste for a living. Waste pickers are vulnerable to various health problems, particularly high risk of occupational health. This study intended to overview the capability of the waste picker to manage the emergency care due to their unsafe working condition. It is a descriptive study involving 48 waste pickers. The study revealed the poor knowledge and practices of the waste pickers in handling their emergency care. Therefore, it exacerbates their health and become riskier to diseases and illness. Improving the knowledge of the waste pickers regarding the emergency care and the provision of health programs accommodating the waste pickers is necessary.
\end{abstract}

Copyright $(0) 2016$ Institute of Advanced Engineering and Science. All rights reserved.

\section{Corresponding Author:}

Loetfia Dwi Rahariyani,

Nursing Programe of Sutopo Surabaya,

Polytechnic of Health Surabaya, Ministry of Health,

Jl. Parang Kusuma, No. 1 Surabaya, Jawa Timur, Indonesia.

Email: rahariyani@yahoo.com

\section{INTRODUCTION}

Health problems in urban are complicated in nature. Waste is alarming in big cities and may trigger health problems for the residents. The Dinas Kebersihan dan Pertamanan Kota Surabaya (DKP)-a department responsible to clean and to maintain the city parks of Surabaya-recorded the production of waste (domestic and industrial) reaching 8000 to 11000 tons a day overloads the landfills and it is predicted the quantity of the waste will significantly increase in the future [1]. However, the waste triggers the phenomenon of waste pickers. Factually, the waste pickers are beneficial for the city's waste management. The waste pickers rummage from house to house potentially reduces the waste dumped into the landfills, which in turns lower the cost of waste management. They are available to sort the recyclable waste (plastic bottles, containers, glasses, etc.) for environmental sustainability. A study conducted by the Housing and Residency Laboratory reported $40 \%$ of the waste is recyclable and $11.75 \%$ was contributed by the waste pickers.

The waste pickers are vulnerable to various health issues and occupational or accident related works. Faridawati reports $60 \%$ of the waste pickers in Bantar Gebang Lanfill experienced dermatology or skin diseases in relation to working condition and hygiene matters [2]. The Community Health Centre (CHC) Marlan Medan claims the waste pickers suffered from upper respiratory tract infection, diarrhoea and $\mathrm{s}$ cabies [3]. The waste pickers in our preliminary study acknowledged of being pricked by used needles, nails, broken glasses or cuts from sharp objects (i.e. metals, glasses). Unfortunately, the waste pickers practiced self-medication and they do not attend healthcare in CHC. They reported the unavailability of health education regarding basic health care and daily emergency care management. 
The Government of Indonesia $(\mathrm{GoI})$ through the Ministry of Health $(\mathrm{MoH})$ introduced the "Healthy People, independence and equity 2014" highlighting the universality of health care, including the waste pickers. According to the Directorate of Community Health, safe community relates to secure environment and being healthy in every cycle of lifespan. Safe Community is a health movement from, by and for the community itself. The waste pickers, as a part of urban community, are eligible for health services and involve into the healthcare. Regarding to the waste pickers, the GoI may concern with the empowerment of the waste pickers in taking care their health, self-management in healthcare, including the emergency one.

This study aims to overview the knowledge of the waste pickers to the daily emergency care, identifies the existing emergency health problems and the capability of the waste pickers to practice the daily emergency care. It is worthwhile to the Government of Indonesia in establishing safe community programs and assisting the waste pickers to overcome their emergency circumstances.

\section{RESEARCH METHOD}

The study used a descriptive approach. A set of open-questionaries were distributed to assess the knowledge and interview is used to evaluate the capability of the waste pickers to manage their emergency healthcare. Some follow up interviews were also conducted to identify daily emergency health issues among the waste pickers and the management taken.

\section{RESULTS AND DISCUSSION}

\subsection{Results}

The study was conduted on 48 waste pickers from the Super Depo Sutorejo (SDS) and Jembatan Merah Plaza (JMP). SDS is a waste sorter facility belong to the municipality of Surabaya and employs waste pickers to sort waste before transport to the landfills. JMP is a Central Business District (CBD) of Surabaya.

Table 1 concludes that waste pickers dominated the age ranges from 36-55 years, mostly were men. Their education level is primary school drop-outs, working duration more than 1 year, and not a Universal Health Coverage membership.

Knowledge level of the waste pickers in emergency care can be seen in Table 2 .

Table 1. The Characteristic of the Waste Pickers

\begin{tabular}{|c|c|c|}
\hline Demography & $\mathrm{N}$ & $\%$ \\
\hline \multicolumn{3}{|l|}{ Age: } \\
\hline $17-35$ & 15 & 31.25 \\
\hline $36-55$ & 24 & 50.00 \\
\hline $56-64$ & 9 & 18.75 \\
\hline \multicolumn{3}{|l|}{ Sex: } \\
\hline Man & 34 & 70.83 \\
\hline Woman & 14 & 29.17 \\
\hline \multicolumn{3}{|l|}{ Education : } \\
\hline Primary School Drop-outs & 28 & 58.33 \\
\hline Primary School & 9 & 18.75 \\
\hline Junior High School & 9 & 18.75 \\
\hline Senior High School & 2 & 4.17 \\
\hline \multicolumn{3}{|l|}{ Working Duration: } \\
\hline$<1$ year & 2 & 4.167 \\
\hline$>1$ year & 46 & 95.83 \\
\hline \multicolumn{3}{|l|}{ Monthly Earning (IRD): } \\
\hline$<1$ million & 25 & 52.08 \\
\hline$>1$ million & 23 & 47.92 \\
\hline \multicolumn{3}{|l|}{ Residency Status } \\
\hline Surabaya & 14 & 29.17 \\
\hline Non- Surabaya & 34 & 70.83 \\
\hline \multicolumn{3}{|c|}{ Universal Health Coverage membership: } \\
\hline UHC Members & 21 & 43.75 \\
\hline Not a UHC Members & 27 & 56.25 \\
\hline
\end{tabular}

Table 2. The Knowledge of the Waste Pickers Regarding to the Daily Emergency Care

\begin{tabular}{lccc}
\hline & Knowledge & N & $\%$ \\
\hline Good & 6 & 12.50 \\
Fair & 18 & 37.50 \\
Poor & 24 & 50.00 \\
\hline
\end{tabular}

IJPHS Vol. 5, No. 4, December 2016 : $415-421$ 
Table 2 shows that $50 \%$ of the waste pickers are poor in understanding the emergency care. There are only $37.5 \%$ of them who had a fair knowledge of the issues. A small percentage $(12.50 \%)$ has sufficient knowledge on facing their emergency situation. Waste pickers are susceptible to diseases and illness in association with their working condition. The incident of non-traumatic or infectious diseases and traumatic cases (i.e. injuries or accidents) are obvious due to an unsafe working environment and poor sanitation and hygiene. Daily Emergency Case among the Waste Pickers in Surabaya can be seen in Table 3.

Table 3. Daily Emergency Case among the Waste Pickers

\begin{tabular}{lcc}
\hline \multicolumn{1}{c}{ Daily Emergency Cases } & $\mathrm{N}$ & $\%$ \\
\hline Non-Trauma/ Infectious Diseases: & & \\
Diarrhoea/ Stomach ache & 9 & 18.75 \\
Fingers Itching & 11 & 22.92 \\
Coughing/ Flu & 6 & 39.59 \\
Dyspnoea & 14 & 12.50 \\
Dizziness/ Unconsciousness & 11 & 29.17 \\
Back pain/ Muscle pain/ Cramp & 7 & 22.92 \\
Others & & 14.58 \\
Trauma and Accident Cases: & 46 & \\
Pricked by sharp materials & 2 & 95.83 \\
Falling down from waste trucks/ slippery & 1 & 4.17 \\
Traffic Road Accidents & 1 & 2.08 \\
Exposure of particles to eyes & & 2.08 \\
\hline
\end{tabular}

Table 3 shows that it revealed the main health problems are close related to the respiration infection such as coughing (39.59\%) and dizziness (29.17\%) and difficulties in breathing (12.50\%). The other non-traumatic problems such as back pain, muscle pain or cramp (22.92\%) and dermatological issues $(22.92 \%)$ are also suffered. Furthermore, regarding the traumatic and accidents, the waste pickers is mostly vulnerable to the penetration of the sharp objects $(95.83 \%)$.

Capability of the Waste Pickers in Managing Daily Emergency Care can be seen in Table 4.

\begin{tabular}{lcc} 
Table 4. The Capability of the Waste Pickers in Managing Daily & Emergency Care \\
\cline { 2 - 3 } \multicolumn{1}{c}{ Daily Emergency Care } & $\mathrm{N}$ & $\%$ \\
\hline Non-Trauma/ Infectious Diseases: & 6 & 12.5 \\
Visit CHC/Clinics/ Hospitals & 18 & 37.5 \\
Self -Medication & 23 & 47.92 \\
Buy Medicines from Kiosk/ herbals & 1 & 2.08 \\
Peers support & & \\
Trauma and Accident Cases: & 2 & 4.17 \\
Visit CHC/Clinics/ Hospitals & 35 & 72.92 \\
Self-Medication & 4 & 8.33 \\
Buy Medicines from Kiosk/ herbals & 7 & 1458 \\
Massage & &
\end{tabular}

Table 4 shows that $47.92 \%$ of the waste pickers prefer to buy medicines or using Jamu (Indonesian traditional herbals) to handle the non-traumatic or infectious diseases. Self-medication is also evident (37.5\%). Self-remedy (72.92\%) is also practiced in dealing the traumatic health issues. The rate of visiting health professionals in handling both kinds of health problems is considerable low and they are more reliant to self-medication by buying medicines nearby kiosks.

\subsection{Discussion}

The domination of the middle age group is inseparable from the nature of the waste picking as it is physically demanding. This condition is important as waste picking is physically demanding surrounded by unhealthy environment. Using hook-metal sticks and big plastic bag or bamboo basket, the waste pickers rummage around the city to collect waste or on the top of the waste piles around the landfill require physical strength.

Even though this study showed the man outnumbered the woman, the presence of the women waste pickers is obvious and significant. According to the Head of the Waste Pickers Association of the East Java Province, from nearly 8,000 waste pickers working in Surabaya municipal, nearly half of them are women [4]. Another typical portrait of the waste pickers are the time spent as a waste picker, their income and place of origin. The majority of the waste pickers have been working in the profession for more than 1 
year. In some studies showed the fact that many waste pickers started involving since their young age following the footprints of their parents.

Furthermore, income generates from waste picking is also a key point to understand the determination to sustain waste picking as a job. This study showed that most of them earns less than 1 million (IRD) or less than USD $\$ 100$ in a month. This monthly earning is far below the 2014 Regional Minimum Wage of the province (IDR 2200000/ month) or approximately USD\$200. It showed that the job is not reliable enough to livelihood sustainability. The studies revealed that most of the waste pickers rent a very cheap room with limited facilities as a survival strategy to the inadequate income. They are living in precarious housing condition with poor access to sanitation or water [2]. In some poor countries, the daily earn of the waste pickers is below the World Bank poverty line. However, in some countries (i.e. China, Brazil), many waste pickers recorded earning exceeding the poverty line of the World Bank [5].

The waste pickers are local migrants from neighbouring cities exceeding the residents of Surabaya. Some studies in Indonesia implied that most of the waste pickers in the major cities come from rural areas [4]. They are not registered as a holder of free health care provided by the GoI through UHC. The Jaminan Kesehatan Masyarakat (JAMKESMAS) or the national free health protection provided by the government and the local scheme, called JAMKESDA unable to fully accommodate the healthcare needed by the waste pickers. Unlike the homeless in New York City the majority have health insurance, which will help them when experiencing health issues or emergency situations [6].

Zoning system of the schemes according to residential boundary obstructs the access of the waste pickers to the free healthcare. The health protection is only applicable within their hometown. Therefore, seeking medication in the health centers in Surabaya is not free and conveys another burden to their existing economic disadvantages.

The economic reason is one of the triggers of the mobility of the people from rural to urban areas which are thousands of them ended up becoming waste pickers [7]. The inaccessibility of the free health care may exacerbates their economic may become a hinder to their dream to pursue a better live in the cities. The background of the waste pickers and their poor access to the public facilities is generally occurring in many developing countries. As local migrants, the waste pickers are sometimes discriminated to the access to health protection and health care [5].

A discussion with the community leaders, the DKP and head of CHCs in Surabaya agreed the significant contribution of the waste pickers to the city waste handling. However, the discussion also agreed that there are no public services are specially established to accommodate the waste pickers. Residency administration also inaccessible due to the high mobility of the waste pickers and they never report to the local authority. The DKP informant explained there was no registration to the waste pickers in landfills, so they did not have plans for their development. The government must provide access to continuous and clear information about the population of waste pickers in order to plan policies and development of new programs [8].

The study also revealed that more than half of the waste pickers working with SDS (Super Depo Sutorejo) under the management of DKP are the UHC (Universal Health Coverage) holders. However, the interview with some of the waste pickers showed that they have not used the UHC card as they do not know the procedures of medication using this scheme and even they do not know the health facilities to go. The head of CHC underlined there are no health care and health education to the waste pickers. She claimed there was no report available for the number and request for health care and education. Consequently, the $\mathrm{CHC}$ has never allocated healthcare and any other means of health services to the waste pickers.

In contrast, the waste pickers at the JMP are mostly unregistered as free UHC recipients funded by the government. Different reasons emerge among the waste pickers. They, for example, believe that they do not need to UHC as they are in good health. Others argued that they are unable to pay the UHC premium and do not know how and where to register for the program. Self-medication the most alternatives, becomes more obvious among the waste pickers and information-sharing from other waste pickers is evident. The barriers patients do not come to health facilities due to poor knowledge, lower income and difficulties transportation on [9].

Most of the waste pickers are poorly educated. Consequently, their knowledge on health and behavior are considerable low. The study reflects this situation. The waste pickers have very limited knowledge in daily emergency management. Knowledge plays an important role as a basis of behavior and attitude. Poor knowledge influences the ability to perform a certain activity or may also decrease the precision of the action taken. In the case of the waste pickers, poor knowledge may influence their decision and action to solve their daily emergency care.

The knowledge and health practice among the waste pickers in dealing their daily health issues is a big concern. A study at Benowo Landfill regarding the knowledge of the women waste pickers showed their poor knowledge and skills to the daily care of reproductive organs [10]. Our previous study among at the

IJPHS Vol. 5, No. 4, December 2016 : 415-421 
private waste dumpsite at Kutisari also showed poor knowledge and practice regarding the reproductive issues among the women waste pickers [4]. In addition, the knowledge of the waste handler at the Cipayung Landfill is poor in regard to the dermatology irritation. However, some positive practices on living health among the waste pickers, a study of Rochgiyanti and colleagues revealed that waste pickers at the Basirih Landfill understand and practices how to live healthily [11].

The traumatic and non-traumatic health issues are the reflections of the unhealthy and unsafe working condition, especially in the landfill. Respiration infection is inseparable from the exposure particles, air pollution, pathogen and inhalation of harmful gases. The exposure of harmful gases such as methane or hydrogen sulphide generates from organic waste may obstruct the respiration system. The clinical symptoms of the acute and chronic poison of hydrogen and carbon sulphide at $50 \mathrm{ppm}$ may trigger the headache, insomnia, balance disorder, coughing, weaknesses, lung oedema, conjunctivitis with pain. Moreover, 500 ppm may trigger consciousness impairment, breathing depression and death at 30-60 minutes exposure. The chronically poison of hydrogen sulphide may decrease the blood pressure, nausea, loss of appetite, weight loss, balance disorder and chronic coughing [10]. A study at the Jatibarang Landfill, Semarang-Indonesia reported the incidence of chest pain, respiration, headache, coughing and breathing pattern shortness as the impacts of excessive inhalation of ammonia gases (NH3) and Hydrogen Sulphide (H2S) [3]. In addition, the respiratory infection was also found among the waste pickers in Delhi, India suffered from respiratory infection, increasing the inflammatory of cell in sputum and peripheral blood leucocytosis [12]. Dermatological issues are also emerging among the waste pickers. Observation of the daily activity of waste picking illustrated that most of the waste picker did not wear adequate protective gears (i.e. water proof gloves, boots, etc.). Even, they wear the similar shabby clothes for weeks without adequate washing or changing. They argued that the safety gears make them uncomfortable to do the job and unintended to provide the tools. In addition, the incidence of non-traumatic diseases was also related to the improper wearing of protective tools. The high exposure of fungi, parasites, and poor personal hygiene practices have been recognized to trigger dermatological diseases such as scabies, candidiasis or different types of tinea (wearing wet shoes or clothes) [11].

The poor practice of occupational health safety may also a driver of the incidence of traumatic injuries such as penetration of sharp objects, broken glasses or cuts from metals, etc. The incidence of various kind of injuries is obvious among the waste pickers.

The high risk of vulnerability may impede the health condition of the waste pickers that may decrease their earnings. Seeing the potential risks, the waste pickers are required to master the basic skills to treat daily emergency care both trauma and non-trauma cases. It is crucial to reduce the severity of the illness. This study resumes the waste pickers attempt to independently resolved their daily emergency care without the assistance of health professionals. The waste pickers claimed that self-medication is the simple and best ways to resolve their daily emergency cares. For example, the waste pickers took medicines from the kiosk as recommended by their friends (i.e. antibiotic, amoxicillin and tetracycline). Others claimed that drinking much water or dark tea or rubbing using balm are effective to reduce the symptoms. The study revealed that most of the waste pickers are unknowledgeable of making larutan gula-garam (a liquid made of sugar and salt) as an emergency treatment for dehydration of diarrhoea. The waste pickers have their own self-medication in dealing with the pricks and cuts. For example, the waste pickers hit their wound using rocks, pressing the wounds to release the blood and rubs it using kerosene or other traditional oils (i.e. minyak tawon). By doing so, they believe in killing the bacteria and reducing the infection. Some waste pickers at the JMP, for example, described that implementing kerosene or oils and dressing the wounds in clothes (mostly the used one) are believed to reduce the bleeding and swollen. This health practices are risky and may worsen the illness. Unhygienic treatment with unsterilized equipment may transport bacteria or another harmful microorganism. It may trigger a tetanus infection or any other secondary infections.

Unfortunately, we have not seen any substantial studies in relation to the way the waste pickers handling their daily emergency cares. However, the self-medication is traditionally practiced among Indonesia. Jamu, for example, has been confirmed by UNESCO as one of the Indonesian traditional heritage on medication. The reasons to undergo self-medication instead of the health professional are varied. The main reason to not seek medication from professionals (i.e. $\mathrm{CHC}$ ) relates to their residency status that hinders their access to free healthcare provided by the local government of Surabaya. Since most of the waste pickers are local migrants and seasonally move to Surabaya for work, it is difficult for them to obtain resident identification. Consequently, they may exclude from any free health services from the government. The Community Health Care (CHC) should be used by all people, as a means to overcome health problems and efforts to improve the health of all people [13]. Moreover, most of the waste pickers do not have the UHC membership in their place of origin. And if they have one, it is also difficult to access the services due to their residency status. The waste pickers also argued that they do not have enough money to pursue medical care from professionals. In some conversation with the waste pickers, preserving money for foods and other 
priorities such as education for their children and having a little investment (i.e. housing, rice field, buying cattle, etc.) in their hometown defeat their health necessities. Therefore, they are becoming ignorance to professional medication services. In addition, they also avoid seeking medication in public health facilities (i.e. CHC or hospitals) due to stigma. They feel uncomfortable with their circumstances, especially the body odors. They aware that the odor of the waste still comes even though they have taken a bath and wear clean clothes.

\section{CONCLUSION}

The waste pickers are highly likely to experience trauma and non-trauma illness and injury as the impacts of their job. Unfortunately, most of the waste pickers have poor knowledge for handling the daily emergency care related to their occupation. Self-medication is a solution to deal with their health issues. The waste pickers also have poor access to health care from the government due to their residency status and they do not obtain the free UHC from the government. The study recommends that the government needs to take feasible steps to accommodate the waste pickers in healthcare to fulfil the mission of a safe community as required by the Universal Health Coverage in January 2019.

\section{ACKNOWLEDGEMENTS}

The authors would like to thank all participants for their willingness to share their experiences and the SDS management to allowing us to collect data in their place.

\section{REFERENCES}

[1] D. D. Brito and S. Dias, "Waste and Gender: Rethinking Relations for Empowerment," 2014.

[2] E. Binion and J. Gutberlet," The effects of handling solid waste on the wellbeing of informal and organized recyclers: a review of the literature," International Journal of Occupational and Environmental Health, vol/issue: 18(1), pp. 9, 2012.

[3] E. Hartini and R. J. Kumalasari, "Factors exposure to ammonia and hydrogen sulfide gas to the health problems of waste pickers at the Landfill Jatibarang Semarang," Semarang, Health Faculty of Fakultas Kesehatan Dian Nuswantoro University, pp. 16, 2013.

[4] Y. Windi, et al, "Reproductive Health of Female Scavengers in Surabaya," Jurnal Kesehatan, vol/issue: 7(4), 2010.

[5] M. Medina, "Waste Picker Cooperatives in Developing Countries," Retrieved 23 June 2015.

[6] Vijayaraghavan M., et al., "Health, Access to Health Care, and Health Care use Among Homeless Women with a History of Intimate Partner Violence," J Community Health, vol. 37, pp. 1032-1039, 2012.

[7] R. L. Jedwab, et al., "Rural Push, Urban Puull New Historical Evidence from Developing Countries Any Washington," Institute for International Economic Policy, vol. 45, 2014.

[8] Gambatase M., et al., "Programmatic Impact of Years of Mortality Surveillance of New York City Homeless Populations," American Journal of Public Health, vol. 103, 2013.

[9] Morgans A. and Burgess S., "Judging a Patient's decision to seek emergency helathcare: clues for Managing increasing patient demand," Australian Health Review, vol. 36, pp. 110-114, 2012.

[10] N. E. Kusumawardhani, "Portraying the Knowledge and behaviors of Personal Hygiene to the Reproductive Organs among the Women Waste Pickers at the Benowo Village, Surabaya," Surya, vol/issue: 1(IX), pp. 6, 2012.

[11] Rochgiyanti, et al., "The Behavior of Waste Pickers in Healthy Life Style in TPA Basirih Banjarmasin City," 2010.

[12] M. R. G. Ray, et al., "Respiratory and General Health Impairments of Ragpickers in India: A Study in Delhi," International Arcieve of Occupational Health, vol. 77, pp. 595-598, 2004.

\section{BIOGRAPHIES OF AUTHORS}

Name : Loetfia Dwi Rahariyani, S.Kp., M.Si.
Addess : Jl. Parang Kusuma No. 1 Surabaya
Email : rahariyani@ yahoo.com
Phone : +6281330405835
Higher Education and Course:
1. Nursing Pedagogy, Nanyang Polytechnic Singapore, 2012
2. Master of Human Development Resources, Airlangga University Surabaya, 2004
3. Bachelor of Nursing, Padjadjaran University Bandung, 1999
4. Nursing Academi, Ministry of Health R I Malang, 1991

IJPHS Vol. 5, No. 4, December 2016 : 415-421 


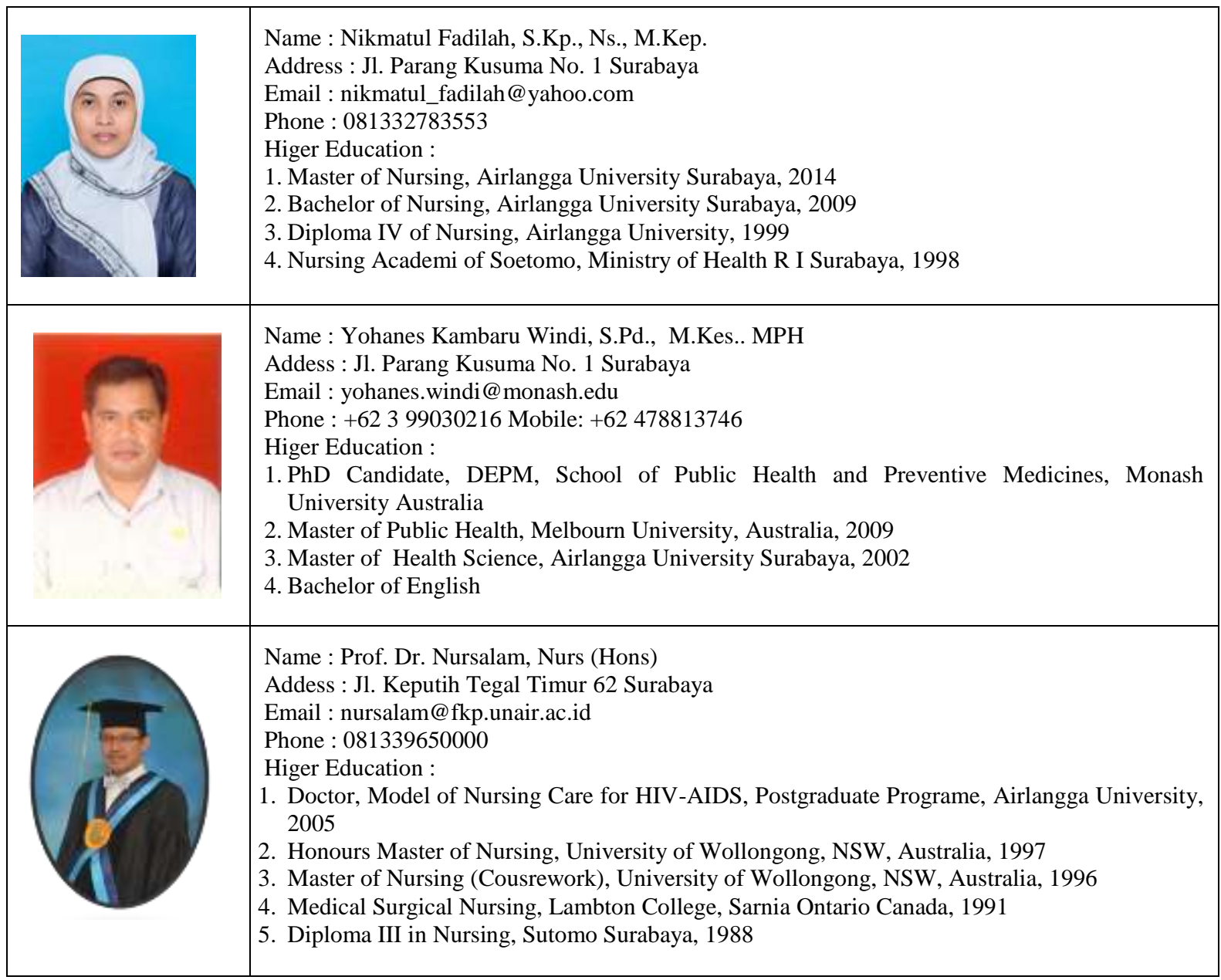

